Int. J. Electrochem. Sci., 11 (2016) 4205 - 4205

\title{
Erratum
}

\section{New Method for Electrochemical Activation of $N$-benzyl Ideneaniline to Dibutyl Phthalate in the Present of Carbon dioxide \\ [Int. J. Electrochem. Sci., 11 (2016) 692-699]}

Qiuju Feng ${ }^{*}$, Honghui Lv, Yanan Zhang, Fanglin Dai, Wenbin Yan

College of Chemistry and Chemical Engineering, Jishou University, Jishou, 416000, China

*E-mail: fqj245@126.com

Received: 3 March 2016 / Accepted: 5 March 2016 / Published: 1 April 2016

This is an erratum regarding the published article (Int. J. Electrochem. Sci., 11 (2016) 692 -699, which has a mistake in the Scheme 1 part.

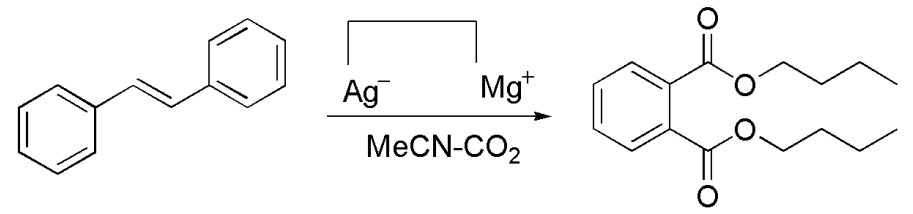

The correct paragraph is as follows:<smiles>C(=N/c1ccccc1)\c1ccccc1</smiles><smiles>C[N+](=O)[O-]</smiles><smiles>CCCCOC(=O)c1ccccc1C(=O)OCCCC</smiles>

This was not noticed at the time by the authors and it is corrected by this erratum now, and we apologize for any inconvenience this may cause.

\section{Reference}

Qiuju Feng, Honghui Lv, Yanan Zhang, Fanglin Dai, Wenbin Yan , Int. J. Electrochem. Sci., 11 (2016) 692-699

(C) 2016 The Author. Published by ESG (www.electrochemsci.org). This article is an open access article distributed under the terms and conditions of the Creative Commons Attribution license (http://creativecommons.org/licenses/by/4.0/). 